\title{
Type 2 diabetes and cardiovascular risk in the UK south Asian community
}

\author{
A. H. Barnett • A. N. Dixon - S. Bellary • M. W. Hanif • \\ J. P. O'Hare • N. T. Raymond • S. Kumar
}

Received: 23 January 2006 / Accepted: 19 May 2006 / Published online: 18 July 2006

(C) Springer-Verlag 2006

\begin{abstract}
A popular hypothesis for the greater prevalence of type 2 diabetes and cardiovascular disease in UK south Asians is that they have an increased susceptibility of developing insulin resistance in response to certain environmental factors, including obesity and adoption of a sedentary lifestyle. Insulin resistance is postulated as a central feature of the metabolic syndrome, culminating in type 2 diabetes, atherosclerotic vascular disease and CHD; a pathway potentially accelerated by migration/ urbanisation. We describe and compare the prevalence of type 2 diabetes, cardiovascular disease and their associated risk factors in UK south Asian and white Caucasian populations to determine possible reasons for the increased preponderance of these diseases in south Asians, and highlight key evidence for optimal risk factor
\end{abstract}

A. H. Barnett conceived the review and had primary responsibility for the initial draft of the manuscript and performing the literature review. All authors contributed to the intellectual content of the review and finalisation of the manuscript.

A. H. Barnett $\cdot$ A. N. Dixon $\cdot$ S. Bellary $\cdot$ M. W. Hanif University of Birmingham,

Birmingham, UK

A. H. Barnett $\cdot$ A. N. Dixon $\cdot$ S. Bellary $\cdot$ M. W. Hanif

Heartlands and Solihull National Health Service

Foundation Trust (Teaching),

Birmingham, UK

J. P. O'Hare • N. T. Raymond · S. Kumar

Department of Medicine, University of Warwick,

Warwick, UK

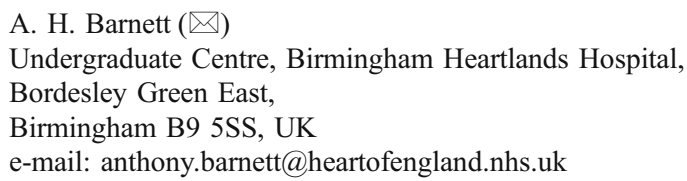

management. Finally, we describe a UK communitybased programme that attempts to reduce the morbidity and mortality from type 2 diabetes and cardiovascular disease in south Asians through a new approach to management.

Keywords Cardiovascular disease $\cdot$ Ethnic .

Metabolic syndrome $\cdot$ Migration $\cdot$ Risk factors $\cdot$ South Asian . Type 2 diabetes
Abbreviations
CRP C-reactive protein
Lp(a) lipoprotein(a)
PAI-1 plasminogen activator inhibitor 1
PC-1 plasma cell membrane glycoprotein 1
UKADS UK Asian Diabetes Study

\section{Introduction}

Following the Second World War, countries such as the Netherlands, France and the UK actively recruited labour from their ex-colonies to fuel their post-war economic recovery. In a similar fashion, wealthy European countries recruited migrant labour from poorer European regions to staff their manufacturing and service industries. More recently, political changes and conflicts between different ethnic groups in central and eastern Europe have affected the size and direction of European migration flows, while flows from non-European countries continue to account for a very sizeable component of migration into Europe. The result is that all the major European countries now have significant ethnic minority populations. 
Ethnic minority populations are diverse, and particular groups may have greater health needs than others. Meeting the health needs of the population requires sensitivity to the many traditions, cultures and religious practices that exist. It is crucial to address specific communities individually according to cultural features such as customs, religion, lifestyle, food and languages. Various social anomalies play an ever-increasing role in the health status of many, and it is important that we do not assume that all ethnic groups are the same or have the same needs.

\section{Summary points}

- The prevalence of type 2 diabetes and cardiovascular disease is significantly increased in immigrant south Asian compared with indigenous populations.

- South Asians generally have a characteristic risk factor profile that is representative of the metabolic syndrome.

- The characteristic risk factor profile of south Asians, consisting of a clustering of the major metabolic abnormalities predictive of type 2 diabetes and cardiovascular disease, suggests it is prudent to hold a high index of suspicion for these conditions in south Asians.

- Conventional approaches to treatment and prevention are based on trials performed in white Caucasian populations and may underestimate risk in south Asians and result in undertreatment.

- New approaches to management that incorporate the specific needs of south Asian communities are required.

\section{The prevalence of type 2 diabetes and cardiovascular disease in south Asian immigrants}

While population migration from the Indian subcontinent countries of India, Pakistan and Bangladesh (South Asia) has occurred to many parts of the world, over 2 million south Asian people have settled in the UK, representing 4\% of the total population [1].

In the absence of large prospective cohort studies, disease burden can only be estimated from prevalence rates observed in cross-sectional studies. These are not strictly comparable because of varying methodology and differing diagnostic criteria. Irrespective of the countries immigrant south Asian populations have settled in and of regional, cultural and religious differences, however, there is strong evidence, gathered over the past half-century, that the prevalence of type 2 diabetes is increased among these individuals compared with indigenous populations [2-6] (Fig. 1).

In most countries, the same is true for the prevalence of cardiovascular disease [7-10], although some reports have shown similar risks to indigenous populations $[6,11,12]$. Although beyond the scope of this review, the prevalence of renal disease is also increased in south Asian compared with indigenous populations, and shares many of the same risk factors as diabetes and cardiovascular disease [13].

In the UK, the risk of type 2 diabetes is increased fourto six-fold in south Asian compared with indigenous populations $[2,4,5,10,14-16]$ (Fig. 2). The age at presentation is also significantly younger, and the condition remains undiagnosed in up to $40 \%$ of south Asian individuals $[15,17]$. As duration of diabetes is one of the strongest risk factors for complications, this places south Asian populations at particular risk.

While not the focus of this review, data suggest that the incidence of type 1 diabetes may also be increased in UK south Asian populations compared with south Asians from the Indian subcontinent [18]. The incidence of type 1 diabetes in children in India and Pakistan is remarkably low [19]. However, a report that focused on an area of the UK with a high south Asian population showed that the incidence of type 1 diabetes increased in south Asian immigrants to the UK from $3.1 / 100,000$ per year to 11.7 / 100,000 per year over a period of just 10 years, thus approaching that of the indigenous population $[18,20]$. Such a rapid change is unlikely to be explained by genetic factors, implying an influence of environmental factors in disease aetiology.

In the UK, the rates of ischaemic heart disease (myocardial infarction and angina) are $30-40 \%$ higher amongst south Asian men than men in the general population [16]. South Asians have an age-standardised mortality rate from CHD that is $50 \%$ higher than that for the total population of England and Wales [21]. Women are proportionally more affected than men (increased by 51 vs $46 \%$, respectively), and the sex difference in coronary mortality is smaller in south Asian than in white Caucasian UK populations [5]. The excess mortality is primarily explained by an increased risk of ischaemic heart disease and type 2 diabetes $[14,22]$.

The excess risk of CHD is seen in all UK south Asian populations [23] and also applies to second-generation immigrants [24]. Much of the excess risk also occurs relatively early $[5,8,21,25]$. In one study, mean age at first myocardial infarction was approximately 5 years lower for south Asian men than for the indigenous UK population (50.2 vs 55.5 years) [25]. Furthermore, the excess mortality in south Asian immigrants steadily increased with decreasing age [8]. Other studies have also reported that south Asians frequently have premature atherosclerosis with more diffuse and aggressive disease than their Caucasian counterparts $[7,26]$.

Studies of rates of type 2 diabetes and CHD in the Indian subcontinent are, to an extent, confounded by limited data and the fact that rates in the Indian subcontinent vary greatly depending on geographical distribution [27] and 


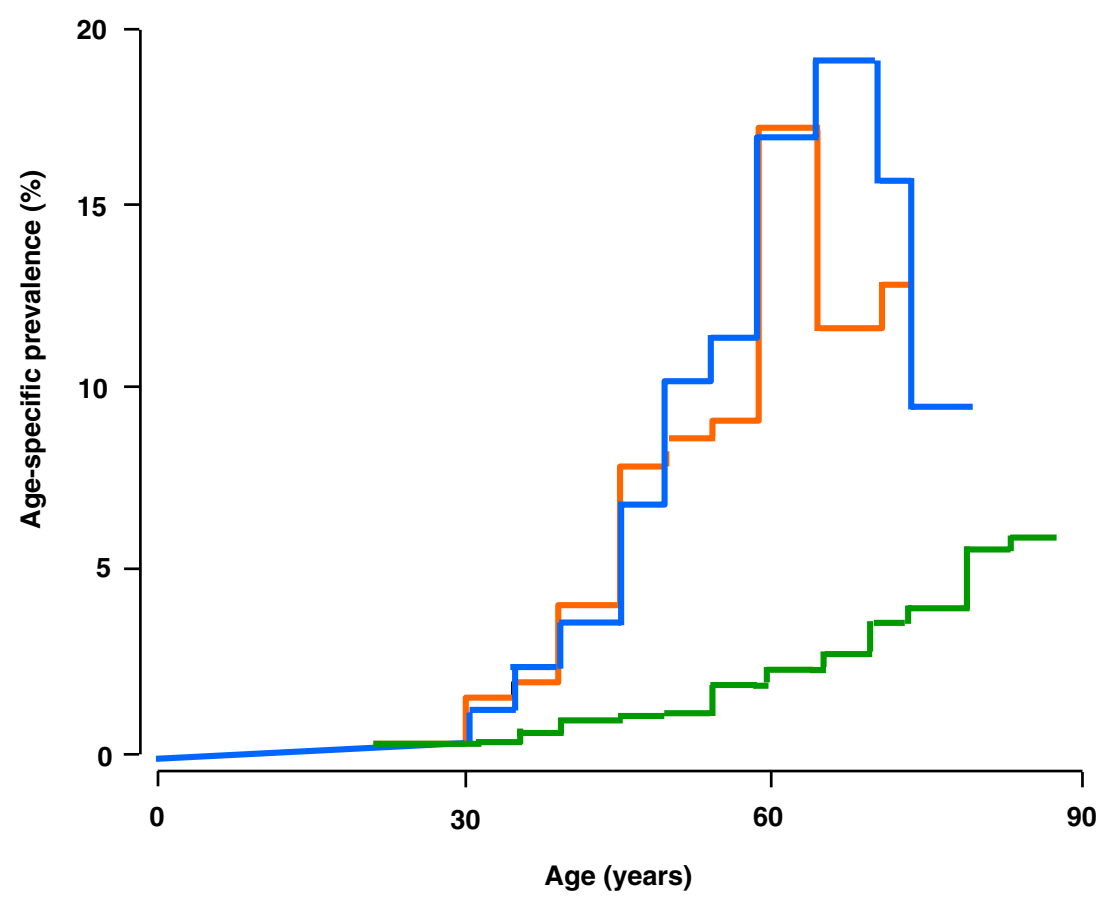

Fig. 1 Age-specific prevalence of type 2 diabetes in people of south Asian extraction living in the UK (Southall Study) [14] and urban India (Darya Ganj Study) [29] compared with the white Caucasian

population (Southall Study) [14]. Blue line, Southall Indians; orange line, Darya Ganj Indians; green line, Southall Europeans. Adapted from [100, Fig. 3.10] socioeconomic status [28]. Several reports suggest, however, that risk factors associated with an urban lifestyle are critical [5, 27, 29, 30]. Indeed, south Asians living in cities in the subcontinent have much higher rates of type 2 diabetes and CHD compared with rural populations $[5,27,30]$, but rates are increasing in both rural and urban areas as lifestyles become more Westernised. A National Urban Diabetes Survey conducted in India in 2000 reported a prevalence of type 2 diabetes of $13.5 \%$ [31].

\section{Insulin resistance, type 2 diabetes and cardiovascular risk}

Defining the risk

While conventional risk factors influence the high CHD rates in south Asians just as they do in indigenous Caucasian populations, the characteristic risk factor profile of south Asians is very different. Furthermore, while CHD risk, to a large extent, is shared across south Asian

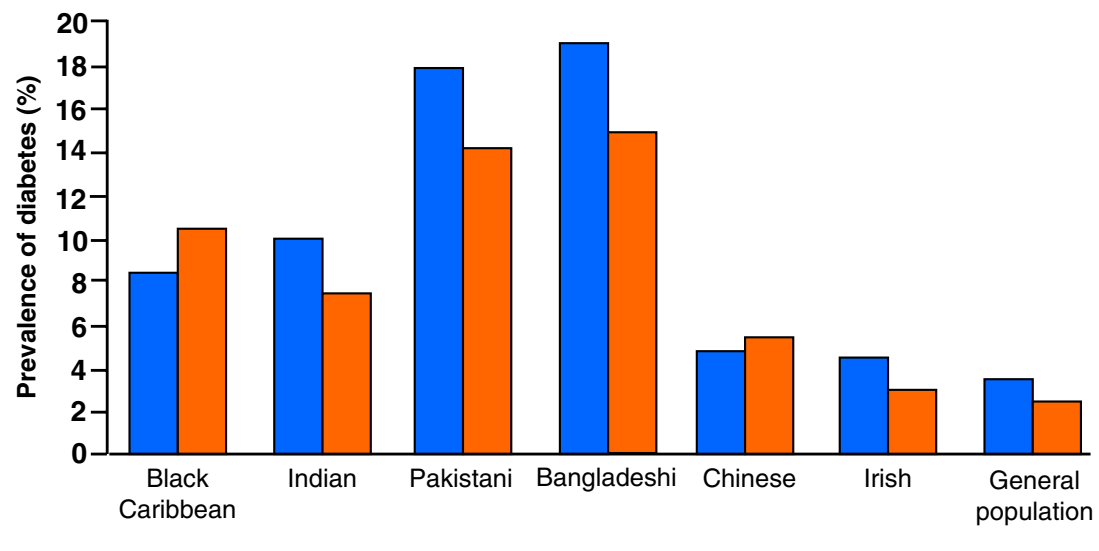

Ethnic group

Fig. 2 Prevalence of diagnosed diabetes by ethnic group in the UK [16]. Blue bar, men; orange bar, women 
subgroups, most risk factors vary enormously [16]. Indians, in particular, are extremely heterogeneous in terms of their risk factor profiles, so findings are likely to vary in different geographical regions and communities. In particular, religion has an important effect. For example, smoking is much less common in Sikhs than in Hindus. The reverse applies to drinking alcohol [16]. Dietary habits are also relatively diverse and are again influenced by religious belief, as well as area of origin in the Indian subcontinent.

Despite the variability in south Asian compared with Caucasian populations and between different subgroups of this population, there is no validated tool for predicting cardiovascular risk. Framingham, Finland Cardiovascular Risk (FINRISK), and Systematic Coronary Risk Evaluation (SCORE) grossly underestimate risk in south Asians [32, 33] (Fig. 3). Similarly, the normal ranges for independent risk factors for CHD (such as blood pressure, BMI and lipid profile) derived from studies on Western populations may be set too high for south Asians. Interventions driven by these ranges may therefore result in under-treatment. There is thus an urgent need for guidelines to be developed that are specifically tailored to the south Asian population. A recent analysis of data from the Health Survey for England 1998 and 1999 was conducted to identify a simple method for adjusting the Framingham equation to estimate coronary risk in south Asians. Adding 10 years to the age of south Asian people was found to be the simplest way of calculating CHD risk while still providing acceptable accuracy [34].

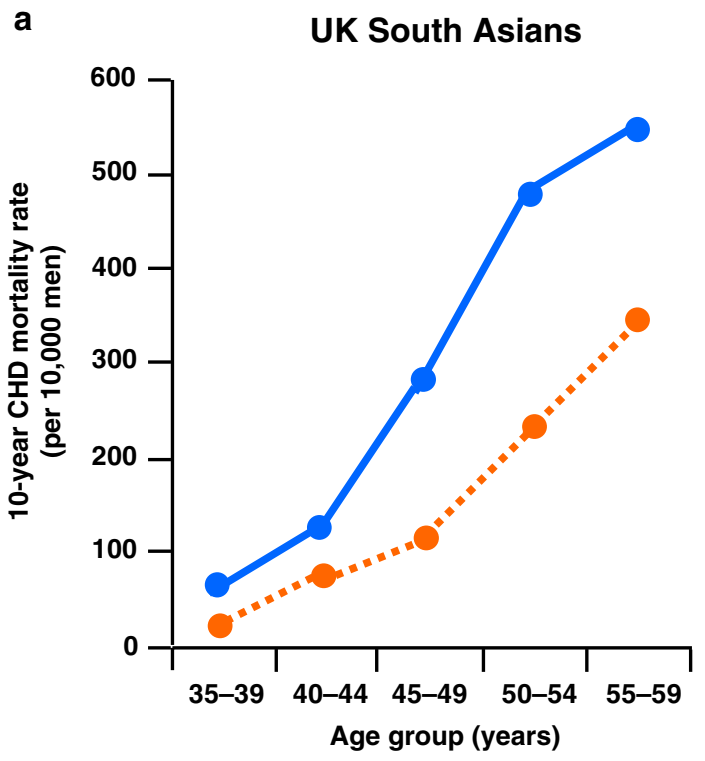

Fig. 3 Coronary heart disease $(C H D)$ risk prediction and observed rates of CHD in UK south Asians (a) and white Europeans (b). Blue line, observed CHD mortality rate; orange line, predicted CHD mortality rate. When the validity of the Framingham functions is evaluated amongst UK south Asians, CHD mortality rates are almost twofold higher amongst south Asian, than white European males. In contrast,
The South Asian risk factor profile

\section{Abdominal obesity}

Increased insulin resistance is more common in south Asians than in Caucasians $[4,9,25,35]$ and manifests early [32, 34-36]. Insulin resistance is postulated to play an important role in the pathogenesis of diabetes and cardiovascular disease. Although genetic factors are also likely to be involved, the major arbiters of insulin resistance are obesity-particularly abdominal/central obesity - and a sedentary lifestyle. The average BMI of UK south Asian individuals is not greater than that of their Caucasian counterparts, but they have a much greater tendency to deposit intra-abdominal fat, which is metabolically active and strongly related to insulin resistance $[4,37,38]$. As such, BMI may underestimate the adiposity of south Asians [39] (Fig. 4). A value of 27.5 or more in a south Asian person has been estimated to be associated with morbidities comparable to those in a Caucasian person with a BMI of 30 [40]. A more accurate predictor of obesity in south Asians is waist circumference, although sagittal diameter (measured using abdominal calipers) may better predict the adverse metabolic profile of the metabolic syndrome [41].

A recent prospective cohort study that compared weight, length, abdominal circumference and skinfold measurements of newborn babies from Mysore, India, with those of newborns from Southampton, UK, reports

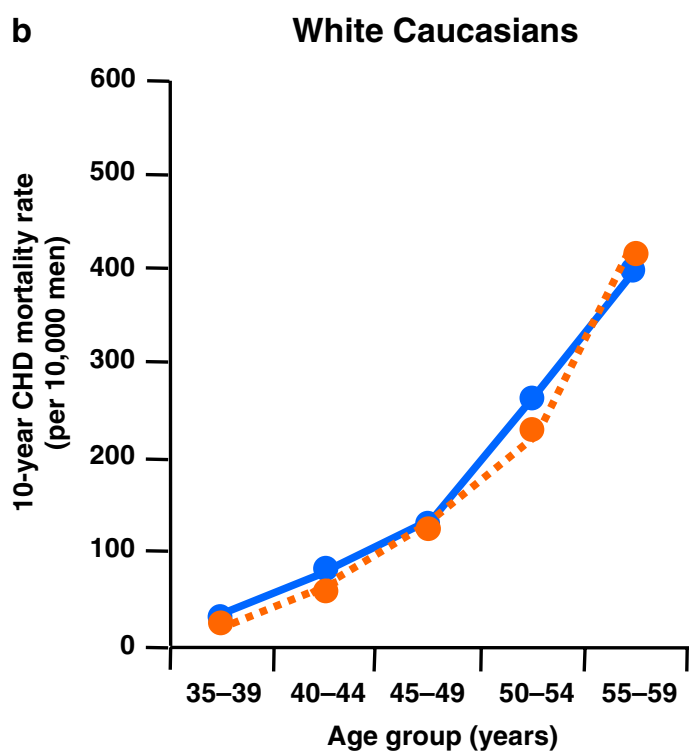

the CHD mortality rate predicted by the Framingham functions amongst a representative sample of UK south Asians is no different to the predicted rate in Europeans. The Framingham functions therefore underestimate the risk of CHD amongst south Asians by approximately $50 \%$. Reproduced with permission from [33] 
Fig. 4 The two individuals in this clinical picture share a nearly identical BMI, but, as dual X-ray absorptiometry imagery shows, the one on the right has substantially more body fat. While the contribution of genes and lifestyle factors may be relevant, the image illustrates the limitations of BMI as a measure of adiposity across populations. Reproduced with permission from [39]

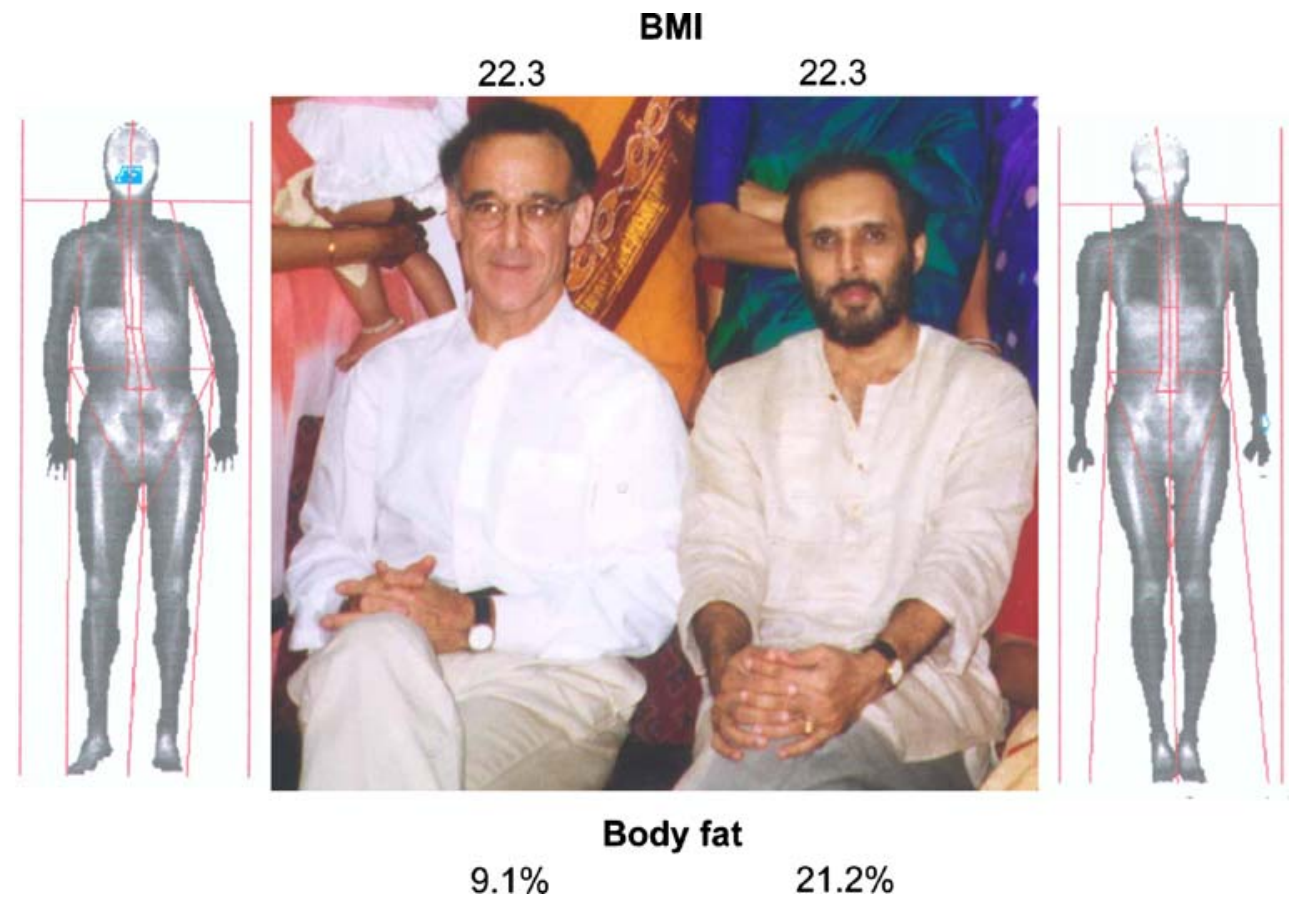

difference $[4,5]$. These studies were based on specific local populations sampled, e.g. from general practitioner lists, and may therefore be subject to sample bias. The large nationally distributed random sample of the Health Survey for England overcomes some of these problems [16]. It shows that after adjustment for age there is some heterogeneity within the UK south Asian population (Table 1). Only Bangladeshi men were significantly (almost $25 \%$ ) less likely to have high blood pressure than men in the general population. Bangladeshi women also had a lower prevalence of high blood pressure than women in the general population, but Pakistani women were significantly more likely $(25 \%)$ to have raised blood pressure [16]. While the prevalence of raised blood pressure in UK south Asians overall may be similar to the indigenous population, it remains a significant risk factor. Age-adjusted data show that approximately one-third of UK adults may have high blood pressure $(\geq 140 / 90 \mathrm{mmHg})$. Furthermore, UK south Asians may be at higher risk of diabetic and cardiovascular complications as a result of raised blood pressure because of their overall adverse risk factor profile.

\section{Smoking}

Smoking in the south Asian population overall is the same or less than white Caucasian males and low in south Asian women $[5,16]$ (Table 1). There are differences between groups, however, with $44 \%$ of Bangladeshis, $26 \%$ of Pakistanis and $23 \%$ of Indians smoking cigarettes, compared with $27 \%$ of men in the general population [16]. 
Table 1 Prevalence of age-standardised risk ratios for cardiovascular disease risk factors in south Asian populations compared with the general population [16]

\begin{tabular}{lllll}
\hline Risk factor (men/women) & \multicolumn{2}{l}{ South Asian ethnicity } & \multicolumn{2}{l}{ General population } \\
\cline { 2 - 4 } & Indian & Pakistani & Bangladeshi \\
\hline Diabetes & $2.97 / 2.88$ & $5.43 / 5.58$ & $5.76 / 5.83$ & $1.0 / 1.0$ \\
Current cigarette smoking & $0.78 / 0.19$ & $0.90 / 0.14$ & $1.57 / 0.07$ & $1.0 / 1.0$ \\
Obesity $\left(\mathrm{BMI}>30 \mathrm{~kg} / \mathrm{m}^{2}\right)$ & $0.66 / 1.02$ & $0.74 / 1.61$ & $0.32 / 0.63$ & $1.0 / 1.0$ \\
WHR $>0.95(\mathrm{men}),>0.85($ women$)$ & $1.48 / 1.73$ & $1.54 / 2.79$ & $1.33 / 3.63$ & $1.0 / 1.0$ \\
High blood pressure & $1.03 / 1.12$ & $0.89 / 1.25$ & $0.74 / 0.89$ & $1.0 / 1.0$ \\
Physical activity & $0.86 / 0.67$ & $0.70 / 0.63$ & $0.55 / 0.35$ & $1.0 / 1.0$ \\
Low HDL cholesterol $(<1.0 \mathrm{mmol} / \mathrm{l})$ & $1.11 / 1.61$ & $1.67 / 2.39$ & $2.68 / 3.67$ & $1.0 / 1.0$ \\
High triglycerides $(\geq 1.6 \mathrm{mmol} / \mathrm{l})$ & $2.56 / 2.28$ & $2.29 / 1.85$ & $1.63 /[1.58]$ & $1.0 / 1.0$ \\
High LDL cholesterol $(\geq 3.0 \mathrm{mmol} / \mathrm{l})$ & $1.63 / 1.74$ & $1.34 / 0.86$ & {$[0.90] / \mathrm{c}$} & $1.0 / 1.0$ \\
High total cholesterol $(\geq 5.0 \mathrm{mmol} / \mathrm{l})$ & $0.99 / 0.86$ & $0.86 / 0.84$ & $0.90 / 0.79$ & $1.0 / 1.0$ \\
\hline
\end{tabular}

Square brackets indicate small sample bases $(<50$ cases $)$

${ }^{a}$ High blood pressure is defined as $\geq 140 / 90 \mathrm{mmHg}$

${ }^{\mathrm{b}}$ Meeting current physical activity guidelines (at least $30 \mathrm{~min}$ of moderate physical activity, defined as energy expenditure $>3.5 \mathrm{kcal} / \mathrm{min}$, on 5 or more days per week)

${ }^{\mathrm{c}}$ Data not shown because of small bases $(<30$ cases $)$

\section{Dyslipidaemia}

While total cholesterol is not significantly greater in UK south Asians (it may, in fact, be less) compared with the white Caucasian population (Table 1) [16, 48, 49], levels remain significantly higher than those seen in the Indian subcontinent [50]. Migration is therefore clearly associated with increased cholesterol levels in this population, and raised total or LDL cholesterol remain important risk factors for the development of CHD in UK south Asians [49]. Furthermore, south Asians have an increased prevalence of atherogenic small, dense LDL cholesterol compared with white Caucasians [51].

Triglycerides are almost always higher in studies on south Asians compared with those on white Caucasians (Table 1) $[4,7,16,45,48,50]$. The majority of studies examining HDL cholesterol concentrations have reported lower levels in south Asian immigrants compared with white Caucasians $[4,7,16,25]$ (Table 1). This pattern of dyslipidaemia, involving raised triglycerides and reduced HDL cholesterol, is typical of the dyslipidaemia associated with diabetes and an important characteristic of the metabolic syndrome.

\section{Emerging risk factors}

A number of emerging risk markers may also play a role in the differing prevalence of type 2 diabetes and cardiovascular disease between south Asian and indigenous populations. Lipoprotein(a) $[\mathrm{Lp}(\mathrm{a})]$ has been designated an emerging risk factor by the US National Cholesterol Education Program, Adult Treatment Panel III [52], and serum concentrations are elevated in south Asians, irrespective of their migrant status $[50,53,54] . \mathrm{Lp}(\mathrm{a})$ is an independent risk factor for early atherosclerosis, and the effect is magnified where LDL cholesterol or the total cholesterol:HDL cholesterol ratio is increased [53]. Levels of $L p(a)$ are largely genetically determined, accounting for over $70 \%$ of the variation in $L p(a)$ in the population $[50,55]$.

Risk markers associated with proinflammatory and prothrombotic states have also attracted attention. Levels of the acute-phase reactant, C-reactive protein (CRP), are strongly associated with CHD [56]. In healthy UK south Asian men, CRP levels were found to be $17 \%$ higher than in European white men, and were accounted for by greater central obesity and insulin resistance [57]. CRP levels in patients with the metabolic syndrome correlate directly with the number of metabolic abnormalities [58]. Differences in CRP levels between south Asians and other ethnic groups have been found in children as young as 10 years of age [59]. Adiposity was found to be a major determinant of the difference in CRP levels, and its strong associations with fibrinogen and HDL cholesterol suggest a role for inflammation in the development of atherosclerosis beginning early in life.

The secretory activity of adipose tissue may play an important role in the proinflammatory and prothrombotic states of the metabolic syndrome. The adipose tissue-derived cytokine adiponectin has regulatory functions on energy metabolism, and concentrations are inversely related to fasting plasma insulin and glucose levels. Low levels compared with indigenous populations suggest that it may be an independent predictor of type 2 diabetes in south Asians [60-62].

Both insulin resistance and type 2 diabetes are associated with endothelial dysfunction, and enhanced platelet aggregation and activation, which favour the development of a prothrombotic state and enhance cardiovascular risk [63]. Markers of a prothrombotic state include high levels of 
fibrinogen and plasminogen activator inhibitor 1 (PAI-1); both have been associated with insulin resistance in south Asian and other populations. Whether this can explain the increased prevalence of type 2 diabetes and cardiovascular disease is controversial, with some [64], but not all [65], studies showing higher levels in south Asians.

A number of studies have investigated the contribution of homocysteine to cardiovascular disease risk. Although south Asians consistently have higher plasma homocysteine levels than control populations, studies are inconsistent, with some showing no difference in levels between patients with and without $\mathrm{CHD}[7,66]$ and others suggesting that homocysteine may be an independent risk factor in south Asians [67]. Interestingly, Chambers et al. suggested that raised homocysteine concentrations in south Asians may be related to reduced vitamin $B_{12}$ and folate levels, implying that increased CHD risk in this group may be reduced by dietary vitamin supplementation [67].

Vitamin D deficiency has been found in some UK south Asian populations [68]. Deficiency is known to impair insulin synthesis and secretion in human and animal models of diabetes, suggesting a possible role in the development of type 2 diabetes [69].

\section{The metabolic syndrome}

A common mechanism is thought to link the increased prevalence of type 2 diabetes and cardiovascular disease in the south Asian population. On the basis of studies comparing UK south Asian and indigenous populations, there is evidence that the pattern of insulin resistance and associated metabolic abnormalities known as the metabolic syndrome might be responsible [4, 70].

It is increasingly recognised that type 2 diabetes is part of a cluster of cardiovascular disease risk factors comprising the metabolic syndrome. The constellation of metabolic abnormalities includes glucose intolerance (type 2 diabetes, IGT, or IFG), insulin resistance, central obesity, dyslipidae-

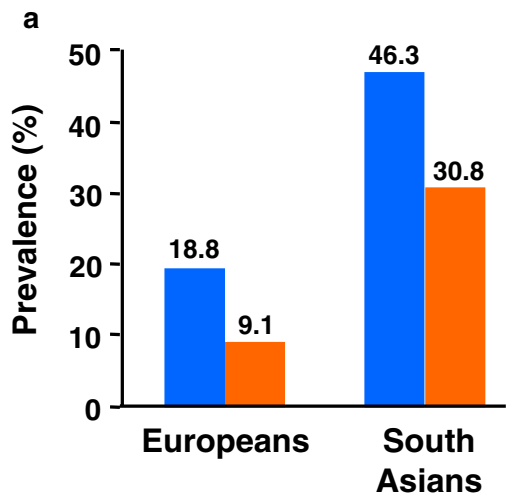

mia and hypertension. Each of these risk factors is an important CHD risk factor in its own right. When grouped together, they are associated with an increased risk of cardiovascular disease, and clustering of the metabolic syndrome components is frequently seen in south Asians [70]. The prevalence of the above risk factors in patients of south Asian extraction suggests they have a particular propensity to develop the metabolic syndrome [71] (Fig. 5), which may explain, at least in part, their increased risk of type 2 diabetes and cardiovascular disease.

There is currently heated debate among leading professional bodies over the definition and clinical significance of the metabolic syndrome [52, 72-74]. Until recently, definitions of the metabolic syndrome did not take into account ethnic-specific variations in risk factors. The International Diabetes Federation has recently provided a definition more applicable to ethnic populations by providing a range for increased waist circumference, which is lower for certain racial groups, e.g. south Asians [72]. Steps such as these are more likely to identify those individuals at risk of cardiovascular disease and type 2 diabetes who are likely to benefit from lifestyle interventions.

\section{Genetic susceptibility}

The genetics of diabetes is almost certainly complex, with a number of genes contributing something to the overall risk. Some of the susceptibility genes for diabetes are likely to be specific to certain populations, while others may be more 'universal', or common to multiple ethnic groups.

Both type 2 diabetes and CHD occur as a result of the complex interplay of genetic susceptibility and environmental factors. Although it is unlikely that distinct genetic factors underlie the inherited risk of type 2 diabetes and CHD in south Asians compared with Caucasians, there may be a higher prevalence of some risk alleles in specific ethnic groups. An example of an allele that may contribute to insulin resistance in south Asians is a polymorphism in the

$$
\text { b }
$$

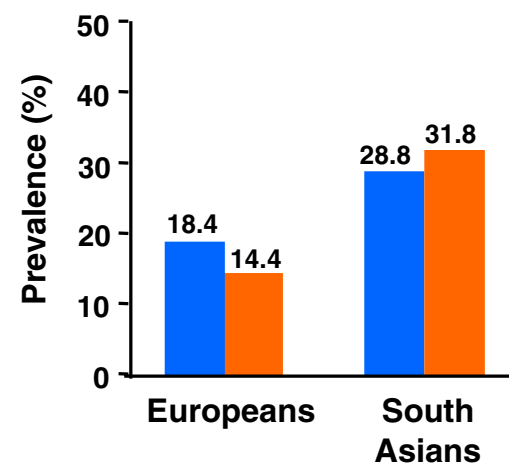

Fig. 5 Age-standardised prevalences of the metabolic syndrome as defined by the World Health Organization $(W H O)$ criteria (a) or the National Cholesterol Education Program (NCEP) criteria (b) by ethnic group. Blue bar, men; orange bar, women. Adapted with permission from [71] 
gene encoding plasma cell membrane glycoprotein-1 (PC-1), which affects insulin signalling by direct interaction with the alpha subunit of the insulin receptor, blocking insulin action. The PC-1 K121Q polymorphism has been associated with a stronger inhibitory effect on the insulin receptor than the wild-type, and occurs with a significantly higher frequency in south Asians compared with Caucasians (33 vs $26 \%$, respectively) [75]. Furthermore, a significantly higher insulin AUC during the OGTT and a lower insulin sensitivity during the hyperinsulinaemic-euglycaemic clamp were found in south Asians with the variant, compared with south Asians with wild-type PC-1 and with Caucasians with or without the polymorphism, suggesting that the variant is associated with primary insulin resistance in migrant south Asians [75].

$\mathrm{Lp}(\mathrm{a})$ is a genetically determined risk factor for CHD, especially when accompanied by increased concentrations of LDL [53]. Some studies have shown that south Asians have

\section{Key features of type 2 diabetes and cardiovascular risk in the UK South Asian community compared with the indigenous population}

\section{High rates}

Four- to six-fold increased risk of type 2 diabetes Three- to four-fold increased risk of ischaemic heart disease

\section{Greater prematurity}

Younger age at presentation of type 2 diabetes

5 -year earlier onset of first myocardial infarction

\section{Greater severity}

Age-standardized mortality rate from CHD is $50 \%$ increased

Premature atherosclerosis with more diffuse and aggressive disease is present

Higher prevalence of glucose intolerance

Insulin resistance, metabolic syndrome, diabetes

\section{Characteristic risk factor profile}

Conventional risk factors

Central obesity

Reduced physical activity

High levels of atherogenic, small dense LDL-cholesterol

High levels of triglycerides

Low levels of HDL cholesterol

Emerging risk factors

Elevated levels of lipoprotein(a), CRP, homocysteine

Low levels of adiponectin

Some evidence of higher levels of fibrinogen and PAI-1 higher plasma levels of $\mathrm{Lp}(\mathrm{a})$, whether living in the UK or in the Punjab, compared with Caucasian subjects [50], presumably because of a higher prevalence of variants in the gene encoding apolipoprotein(a) that increase levels of the lipoprotein [53]. The capacity of a migrating population to rapidly acquire a raised LDL cholesterol level owing to changes in dietary patterns and/or lifestyle shows how a genetically determined CHD risk factor can be transformed into a more potent risk factor by westernisation.

\section{Evidence base for treatment}

Individuals from ethnic groups are not adequately targeted for risk-reduction strategies, including screening and treatment for dyslipidaemia, hypertension and diabetes. In addition, few studies have included enough individuals from these groups to confirm the value of risk-reducing interventions, such as lipid-lowering therapy.

However, while conventional risk factors, with the exception of type 2 diabetes, may not fully explain the increased cardiovascular disease risk in south Asian populations, this does not diminish their importance in disease causation [76]. Furthermore, retrospective analyses of CHD and risk factor epidemiological studies from the Indian subcontinent have reported an increasing prevalence of these conventional risk factors [30,31], which correlates positively with an increasing CHD prevalence in India [77].

Minority ethnic groups are susceptible to the same obesity-related health problems that affect the majority of the UK population. The energy intake as fat for UK south Asians is comparable to that for white Caucasians, but is significantly higher than that for non-migrant south Asians [78]. Some studies have hypothesised that high rates of CHD among these ethnic groups are due to the use of ghee (clarified butter) and other cooking oils [79, 80]. This does not, however, apply to all subgroups of the south Asian community [2]. Encouragement to reduce saturated and total fat intake is sensible, but reduced salt intake, and a diet rich in fruits, vegetables and high in fibre are also important [81] (Table 2).

Moderate to high levels of physical activity are known to significantly reduce the risk of CHD. Exercise can improve HDL cholesterol levels [82] and ameliorate insulin resistance [83] in south Asian as well as white Caucasian populations.

It can be argued that all patients with type 2 diabetes should be treated from a secondary prevention point of view. Following the publication of the Heart Protection Study [84] and the Collaborative Atorvastatin Diabetes Study (CARDS) [85], many now argue that all patients with type 2 diabetes should be prescribed a statin, particularly those of south Asian descent. It also follows that even nondiabetic individuals of south Asian extraction should 
Table 2 Lifestyle guidelines and desirable levels of risk factors for prevention of CHD in south Asians

\begin{tabular}{ll}
\hline Risk factor/lifestyle change & Desirable level \\
\hline BMI $\left(\mathrm{kg} / \mathrm{m}^{2}\right)$ & $18.5-23.0$ \\
Total cholesterol & $4.4 \mathrm{mmol} / 1(170 \mathrm{mg} / \mathrm{dl})$ \\
LDL cholesterol & $2.3 \mathrm{mmol} / 1(90 \mathrm{mg} / \mathrm{dl})$ \\
Triglycerides & $<1.7 \mathrm{mmol} / 1(<150 \mathrm{mg} / \mathrm{dl})$ \\
HDL cholesterol & $>0.9 \mathrm{mmol} / 1(>35 \mathrm{mg} / \mathrm{dl})$ \\
Fasting blood glucose & $>7.8 \mathrm{mmol} / 1(>140 \mathrm{mg} / \mathrm{dl})$ \\
& signifies diabetes \\
Postprandial blood glucose & $>11.1 \mathrm{mmol} / 1(>200 \mathrm{mg} / \mathrm{dl})$ \\
& signifies diabetes \\
Diet & An intake of $400 \mathrm{~g} / \mathrm{day}$ fruit, \\
& vegetables and legumes; mustard or \\
& soybean oil $(25 \mathrm{~g} / \mathrm{day})$ instead of \\
& hydrogenated fat, coconut oil \\
& or butter \\
Exercise & Moderate physical activity \\
& $(1255 \mathrm{~kJ} /$ day $)$ \\
Lifestyle changes & Cessation of tobacco consumption \\
& and moderation of alcohol intake \\
\hline
\end{tabular}

Risk factor levels are based on levels in low-risk rural populations in India [81]

receive a statin if they are at sufficiently high cardiovascular risk; for patients of south Asian origin, many advocate adding a correction factor of $50 \%$ to the value obtained using standard cardiovascular risk tables [86].

It should be noted, however, as is often the case with major clinical trials, that south Asian populations were not represented in any of the major statin trials and, therefore, definitive evidence for dyslipidaemia management is still lacking in this group. The dyslipidaemia of the metabolic syndrome (tendency towards low HDL cholesterol and raised triglycerides) is typical of the lipid profile of many south Asians, and is similar to that of patients studied in the Veterans Affairs Cooperative Studies Program High-Density Lipoprotein Cholesterol Intervention Trial [87]. In this trial, increases in HDL cholesterol and decreases in triglyceride levels were achieved with the fibrate gemfibrozil, and a concomitant reduction in cardiovascular mortality was observed in patients with and without diabetes. Further evidence for the benefits of fibrates in the management of patients with type 2 diabetes has been provided by the results of the Fenofibrate Intervention and Event Lowering in Diabetes study, in which fenofibrate was associated with a reduction in major coronary events [88]. In this study, fenofibrate was well tolerated, both alone and in combination with statins. There is considerable rationale for combining a fibrate or nicotinic acid derivative with statin therapy in patients with the metabolic syndrome [8890]. This approach may only be acceptable, however, in individuals with significant dyslipidaemia, given the poten- tial for an increased risk of side effects with statin + fibrate or statin + nicotinic acid combinations.

The evidence base for aspirin usage is not as good as that for statins, but the Hypertension Optimal Treatment study demonstrated a $15 \%$ risk reduction for cardiovascular endpoints in patients with type 2 diabetes treated with low-dose aspirin, albeit with an increased risk of (non-fatal) haemorrhage [91]. In practice, the evidence suggests that all patients with type 2 diabetes over 50 years of age should be treated with low-dose aspirin $(75 \mathrm{mg})$ once blood pressure is controlled (systolic $<150 \mathrm{mmHg}$ ). In south Asian patients with type 2 diabetes who are aged less than 50 years, aspirin should be offered if there is a history of cardiovascular disease or they have at least one other cardiovascular risk factor (unless there is a contraindication or tolerability problem) [92].

\section{Cultural issues}

Meeting the health needs of the population requires sensitivity to the many traditions, cultures and religious practices that exist in Britain today. A number of organisations, such as the Department of Health, Diabetes UK, the South Asian Health Foundation and the British Heart Foundation, have set objectives for meeting the challenge of dealing with type 2 diabetes and cardiovascular disease in ethnic minority populations. These include increasing awareness of diabetes and CHD through greater community-based activities; providing and promoting more culturally specific information for groups at increased risk; greater partnership with relevant community organisations; and funding of community and research projects.

A number of cultural and social factors may be linked to the increased prevalence of type 2 diabetes and CHD in south Asian populations, including lack of knowledge, poor use of health resources, and a different attitude towards chronic diseases. Lack of diabetes-related knowledge has been observed among UK south Asians [93-96]. This could result from a communication gap between patients and their care providers or problems with literacy. A disproportionately high number of people from ethnic minority communities are on a low income. In addition, more than half live in local authority areas that are among the most deprived in the UK.

It is also clear that many people of south Asian extraction are not using health resources adequately and may be less likely to be prescribed statins and other cardioprotective treatments [97-99]. This is despite a higher CHD morbidity and mortality compared with white Caucasians.

It is crucial to address specific communities individually according to cultural features such as customs, religion, lifestyle, food and languages. Language may be a barrier for some south Asians (particularly in older Asian women) 
to fully access mainstream health services. Educational interventions should target not only high-risk, middle-aged people, but also adolescents and young adults, so that awareness of the disease and its effects are appreciated at an early age. Interventions to promote physical activity and control obesity among south Asian communities should be consistent with lifestyles, diet and cultural considerations.

New approaches to management need to be developed that take into account the specific needs of south Asian communities, with the long-term aim of reducing morbidity and mortality from diabetes and cardiovascular disease. It is this awareness that led to the United Kingdom Asian Diabetes Study (UKADS) [98].

\section{UKADS}

UKADS was designed to test the hypothesis that structured, culturally sensitive care for type 2 diabetes in south Asian communities can improve cardiovascular risk factors and, ultimately, cardiovascular endpoints in a cost-effective manner [98]. The trial included 361 patients of south Asian ethnicity with type 2 diabetes and one other risk factor (hypertension, elevated total cholesterol or poor glycaemic control) from six general practices in Birmingham and Coventry (UK). Patients were randomised to either enhanced or conventional care.

In the group receiving enhanced care, Asian Link Workers contacted patients to encourage clinic attendance, organised educational sessions, and attended clinics to facilitate patient understanding and compliance. Patients also had additional sessions with the practice nurse, with input from community diabetes specialist nurses, working to treatment protocols and targets for diabetes, hypertension and dyslipidaemia. The group receiving conventional care was treated to the same protocols, but received no additional practice resources.

After 1 year (Table 3) there was a significantly greater reduction in mean systolic blood pressure, diastolic blood pressure and total cholesterol in the enhanced care group. There was no significant difference in $\mathrm{HbA}_{1 \mathrm{c}}$ between the groups. The use of pharmacological treatments and compliance with therapy were both higher in the enhanced care group.
Following the relative success of the pilot trial, a followon study has commenced to determine whether this approach can produce sustained results in a larger population. The study has recruited approximately 100 south Asian patients with type 2 diabetes from each of 18 practices in Birmingham and Coventry (around 1800 patients), as well as 500 white Caucasian patients with type 2 diabetes. The study is planned to run for 3 years after randomisation. In addition to recording cardiovascular risk markers and major outcomes, a full health economic evaluation will be performed to determine whether such an approach is economically viable.

\section{Conclusion}

Type 2 diabetes, cardiovascular disease and their associated complications account for a high proportion of avoidable morbidity and premature mortality in UK south Asians. Furthermore, all indicators suggest that the problem will increase, as second-generation immigrants display many of the same risk characteristics as their parents and grandparents. In addition, with the aging of these populations, the impact of ethnicity on the need for care services will become even greater. Health authorities with a high proportion of south Asian populations are likely to need considerable additional investment to meet future needs. If resource considerations constrain service provision, ethnic minorities will be particularly disadvantaged. Measures to control diabetes and cardiovascular disease in south Asian communities therefore urgently need to be addressed to forestall a significant increase in the associated human and economic costs. It should also be noted that while this review predominantly focuses on UK south Asians, migration from the Indian subcontinent has occurred to many parts of the world, and the prevalence of type 2 diabetes and cardiovascular disease is significantly increased in these populations, irrespective of the countries they have settled in. The issues discussed in this review are therefore equally applicable to other migrant south Asian communities. In addition, the epidemic in south Asians abroad is likely to forewarn of what may happen on the
Table 3 Risk factor change over 1 year of follow-up in the UKADS study [98]

\begin{tabular}{lllll}
\hline & $\begin{array}{l}\text { Intervention mean } \\
\text { difference }\end{array}$ & $\begin{array}{l}\text { Control mean } \\
\text { difference }\end{array}$ & Difference $(95 \%$ CI $)$ & $p$ value \\
\hline $\begin{array}{l}\text { Systolic blood } \\
\text { pressure }\end{array}$ & -6.69 & -2.11 & $-4.58(-8.84$ to -0.32$)$ & 0.035 \\
$\begin{array}{l}\text { Diastolic blood } \\
\text { pressure }\end{array}$ & -3.14 & +0.28 & $-3.41(-5.66$ to -1.16$)$ & 0.003 \\
$\begin{array}{l}\text { Total cholesterol } \\
\mathrm{HbA}_{1 \mathrm{c}}\end{array}$ & -0.51 & -0.12 & $-0.38(-0.65$ to -0.12$)$ & 0.005 \\
& -0.23 & -0.20 & $-0.03(-0.36$ to +0.30$)$ & 0.866 \\
\hline
\end{tabular}


Indian subcontinent as standards of living rise and the adoption of Western lifestyles increases.

Approaches to the problem should be at population and individual levels. The preponderance of insulin resistance and a highly atherogenic risk factor profile in south Asian populations require a high index of suspicion of type 2 diabetes and CHD, and aggressive prevention. An intensive programme of primary prevention should be initiated early and, in particular, the promotion of efforts to reduce excess caloric intake and increase energy expenditure.

For high-risk groups, enhanced care may be necessary. Although established risk factor interventions such as statin therapy are undoubtedly of value in south Asian populations, data for ethnic minority populations, and south Asians in particular, are lacking from the majority of cardiovascular risk factor intervention trials. Therefore, conventional approaches to the testing and treatment of risk factors are not likely to be sufficient in the south Asian population. The UKADS pilot demonstrated that in 1 year, improvements in blood pressure and total cholesterol can be achieved with a structured, culturally sensitive, communitybased approach to cardiovascular risk management in a population of south Asians with type 2 diabetes. The same strategy, but with more aggressive targets and in a greater number of individuals, is now being evaluated to determine if this approach is economically viable on a larger scale.

Acknowledgements We would like to acknowledge the help and support of all general practitioners, practice nurses, and other health care workers involved in this study. We would also like to thank the UKADS Executive Committee for all their help and advice-in addition to the authors of this review we include S. Mughal, L. Dodd, Y. Ahmad, K. Mishra, A. Jones and A. Szczepura.

We would also like to thank the following companies for providing financial support in the form of grants for the UKADS. These include Pfizer, Aventis UK (now sanofi-aventis), Servier Labs UK, Merck \& Co., MSD/Schering-Plough, Takeda UK, Roche, Boehringer Ingelheim, Eli Lilly, Novo Nordisk, Bristol Myers Squibb, Daiichi Sankyo UK and Sanofi-Synthelabo (now sanofi-aventis).

Duality of interest We declare that we have no duality of interest.

\section{References}

1. Office for National Statistics (2001) 2001 Census. Available from http://www.statistics.gov.uk/, last accessed May 2006

2. Cappuccio FP, Cook DG, Atkinson RW, Wicks PD (1998) The Wandsworth heart and stroke study. A population-based survey of cardiovascular risk factors in different ethnic groups. Methods and baseline findings. Nutr Metab Cardiovasc Dis 8:371-385

3. Jenum AK, Holme I, Graff-Iversen S, Birkeland KI (2005) Ethnicity and sex are strong determinants of diabetes in an urban Western society: implications for prevention. Diabetologia 48: 435-439

4. McKeigue PM, Shah B, Marmot MG (1991) Relation of central obesity and insulin resistance with high diabetes prevalence and cardiovascular risk in South Asians. Lancet 337:382-386
5. McKeigue PM, Ferrie JE, Pierpoint T, Marmot MG (1993) Association of early-onset coronary heart disease in South Asian men with glucose intolerance and hyperinsulinaemia. Circulation $87: 152-161$

6. Mohanty SA, Woolhandler S, Himmelstein DU, Bor DH (2005) Diabetes and cardiovascular disease among Asian Indians in the United States. J Gen Intern Med 20:474-488

7. Anand SS, Yusuf S, Vuksan V et al (2000) Differences in risk factors, atherosclerosis, and cardiovascular disease between ethnic groups in Canada: the Study of Health Assessment and Risk in Ethnic groups (SHARE). Lancet 356:279-284

8. Balarajan R (1991) Ethnic differences in mortality from ischaemic heart disease and cerebrovascular disease in England and Wales. BMJ 302:560-564

9. McKeigue PM, Marmot MG (1988) Mortality from coronary heart disease in Asian communities in London. BMJ 297:903

10. Wild S, McKeigue P (1997) Cross sectional analysis of mortality by country of birth in England and Wales, 1970-92. BMJ 314:705

11. UK Prospective Diabetes Study Group (1998) Ethnicity and cardiovascular disease. The incidence of myocardial infarction in white, South Asian, and Afro-Caribbean patients with type 2 diabetes (UK Prospective Diabetes Study 32). Diabetes Care 21:1271-1277

12. Woodward M, Zhang X, Barzi F et al (2003) The effects of diabetes on the risks of major cardiovascular diseases and death in the Asia-Pacific region. Diabetes Care 26:360-366

13. Fischbacher CM, Bhopal R, Rutter MK et al (2003) Microalbuminuria is more frequent in South Asian than in European origin populations: a comparative study in Newcastle, UK. Diabet Med 20:31-36

14. Mather HM, Keen H (1985) The Southall Diabetes Survey: prevalence of known diabetes in Asians and Europeans. Br Med J (Clin Res Ed) 291:1081-1084

15. Simmons D, Williams DR, Powell MJ (1989) Prevalence of diabetes in a predominantly Asian community: preliminary findings of the Coventry Diabetes Study. BMJ 298:18-21

16. Health Survey for England (2001) The health of minority ethnic groups ' 99 . The Stationery Office, London

17. UK Prospective Diabetes Study Group (1994) UK Prospective Diabetes Study XII: differences between Asian, Afro-Caribbean and white Caucasian type 2 diabetic patients at diagnosis of diabetes. Diabet Med 11:670-677

18. Bodansky HJ, Staines A, Stephenson C et al (1992) Evidence for an environmental effect in the aetiology of insulin dependent diabetes in a transmigratory population. BMJ 304:1020-1022

19. Staines A, Hanif S, Ahmed S et al (1997) The incidence of insulin dependent diabetes mellitus in Karachi, Pakistan. Arch Dis Child 76:121-123

20. Feltbower RG, Bodansky HJ, McKinney PA et al (2002) Trends in the incidence of type 1 diabetes in south Asians and other children in Bradford, UK. Diabet Med 19:162-166

21. Chaturvedi N, Fuller JH (1996) Ethnic differences in mortality from cardiovascular disease in the UK: do they persist in people with diabetes? J Epidemiol Community Health 50:137-139

22. Wilkinson P, Sayer J, Laji K et al (1996) Comparison of case fatality in south Asian and white patients after acute myocardial infarction: observational study. BMJ 312:1330-1333

23. McKeigue PM, Miller GJ, Marmot MG (1989) Coronary heart disease in South Asians overseas - review. J Clin Epidemiol 422:597-609

24. Shaukat N, DeBono DP, Jones DR (1994) A comparison of risk factors in south Asian and north European coronary artery patients with their young male offspring. Br Heart J 71:27

25. Hughes LO, Raval U, Raftery EB (1989) First myocardial infarctions in Asian and white men. BMJ 298:1345-1350 
26. Lowry PJ, Glover DR, Mace PJ, Littler WA (1984) Coronary artery disease in Asians in Birmingham. Br Heart J 52:610-613

27. Chadha SL, Radhakrishnan S, Ramachandran K, Kaul U, Gopinath N (1990) Epidemiological study of coronary heart disease in urban population of Delhi. Indian J Med Res 92:424-430

28. Gupta R, Gupta VP, Ahluwalia NS (1994) Educational status, coronary heart disease, and coronary risk factor prevalence in a rural population of India. BMJ 309:1332-1336

29. Verma NP, Mehta SP, Madhu S, Mather HM, Keen H (1986) Prevalence of known diabetes in an urban Indian environment: the Darya Ganj Diabetes Survey. Br Med J (Clin Res Ed) 293:423-424

30. Ramachandran A, Snehalatha C, Baskar AD et al (2004) Temporal changes in prevalence of diabetes and impaired glucose tolerance associated with lifestyle transition occurring in the rural population in India. Diabetologia 47:860-865

31. Ramachandran A, Snehalatha C, Kapur A et al (2001) High prevalence of diabetes and impaired glucose tolerance in India: National Urban Diabetes Survey. Diabetologia 44:1094-1101

32. Bhopal R, Fischbacher C, Vartiainen E, Unwin N, White M, Alberti G (2005) Predicted and observed cardiovascular disease in South Asians: application of FINRISK, Framingham and SCORE models to Newcastle Heart Project data. J Public Health (Oxf) 27:93-100

33. Chambers JC, Wrigley J, Kooner JS (2000) Evaluation of the Joint British Societies coronary heart disease risk calculator in UK South Asians. Heart 83(Suppl):43A

34. Aarabi M, Jackson PR (2005) Predicting coronary risk in UK South Asians: an adjustment method for Framingham-based tools. Eur J Cardiovasc Prev Rehabil 12:46-51

35. Ehtisham S, Crabtree N, Clark P, Shaw N, Barrett T (2005) Ethnic differences in insulin resistance and body composition in UK adolescents. J Clin Endocrinol Metab 90:3963-3969

36. Whincup PH, Gilg JA, Papacosta O et al (2002) Early evidence of ethnic differences in cardiovascular disease risk: cross sectional comparison of British South Asian and white children. BMJ 324:635

37. McTernan P, Kumar S (2004) Pathogenesis of obesity-related type 2 diabetes. In: Barnett AH, Kumar S (eds) Obesity and diabetes. Wiley, Chichester, pp 49-78

38. Ramachandran A, Snehalatha C, Dharmaraj D, Viswanathan M (1992) Prevalence of glucose intolerance in Asian Indians. Urban-rural difference and significance of upper body adiposity. Diabetes Care 15:1348-1355

39. Yajnik CS, Yudkin JS (2004) Clinical picture. The Y-Y paradox. Lancet 363:163

40. Working Party of the Royal College of Physicians (2004) Storing up problems: the medical cure for a slimmer nation. Royal College of Physicians, London, p 3

41. Valsamakis G, Chetty R, Anwar A, Banerjee AK, Barnett A, Kumar S (2004) Association of simple anthropometric measures of obesity with visceral fat and the metabolic syndrome in male Caucasian and Indo-Asian subjects. Diabet Med 21:1339-1345

42. Krishnaveni GV, Hill JC, Veena SR et al (2005) Truncal adiposity is present at birth and in early childhood in south Indian children. Indian Pediatr 42:527-538

43. Godfrey KM, Barker DJP (2000) Fetal nutrition and adult disease. Am J Clin Nutrition 71:1344S-1352S

44. Dhawan J, Bray CL (1997) Asian Indians, coronary artery disease, and physical exercise. Heart 78:550-554

45. Fischbacher CM, Hunt S, Alexander L (2004) How physically active are South Asians in the United Kingdom? A literature review. J Public Health (Oxf) 26:250-258

46. Cruickshank JK, Jackson SH, Bannan LT, Beevers DG, Beevers M, Osbourne VL (1983) Blood pressure in black, white and Asian factory workers in Birmingham. Postgrad Med J 59: $622-626$
47. Mather HM, Chaturvedi N, Fuller JH (1998) Mortality and morbidity from diabetes in South Asians and Europeans: 11-year follow-up of the Southall Diabetes Survey, London, UK. Diabet Med 15:53-59

48. Davis TM, Cull CA, Holman RR; UK Prospective Diabetes Study (UKPDS) Group (2001) Relationship between ethnicity and glycemic control, lipid profiles, and blood pressure during the first 9 years of type 2 diabetes: UK Prospective Diabetes Study (UKPDS 55). Diabetes Care 24:1167-1174

49. Hughes LO, Woiciechowski AP, Raftery EB (1990) Relationship between plasma cholesterol and coronary artery disease in Asians. Atherosclerosis 83:5-20

50. Bhatnager D, Anand IS, Durrington PN et al (1995) Coronary risk factors in people from the Indian subcontinent living in west London and their siblings in India. Lancet 345:405-409

51. Kulkarni KR, Markovitz JH, Nanda NC, Segrest JP (1999) Increased prevalence of smaller and denser LDL particles in Asian Indians. Arterioscler Thromb Vasc Biol 19:2749-2755

52. National Cholesterol Education Program (NCEP) Expert Panel on Detection, Evaluation, and Treatment of High Blood Cholesterol in Adults (Adult Treatment Panel III) (2002) Third Report of the National Cholesterol Education Program (NCEP) Expert Panel on Detection, Evaluation, and Treatment of High Blood Cholesterol in Adults (Adult Treatment Panel III) final report. Circulation 106:3143-3421

53. Misra A, Vikram NK, Arya S et al (1998) Lipoprotein(a) is an independent risk factor for coronary artery disease in NIDDM patients in South India. Diabetes Care 21:1819-1823

54. Shaukat N, de Bono DP, Jones DR (1995) Like father like son? Sons of patients of European or Indian origin with coronary artery disease reflect their parents' risk factor patterns. Br Heart J 74:318-323

55. Anonymous (1991) Lipoprotein (a). Lancet 337:397-398

56. Ridker PM (2001) High-sensitivity C-reactive protein: potential adjunct for global risk assessment in the primary prevention of cardiovascular disease. Circulation 103:1813-1818

57. Chambers JC, Eda S, Bassett $P$ et al (2001) C-reactive protein, insulin resistance, central obesity, and coronary heart disease risk in Indian Asians from the United Kingdom compared with European whites. Circulation 104:145-150

58. Forouhi NG, Sattar N, McKeigue PM (2001) Relation of Creactive protein to body fat distribution and features of the metabolic syndrome in Europeans and South Asians. Int J Obes Relat Metab Disord 25:1327-1331

59. Cook DG, Mendall MA, Whincup PH et al (2000) C-reactive protein concentration in children: relationship to adiposity and other cardiovascular risk factors. Atherosclerosis 149:139-150

60. Mohan V, Deepa R, Pradeepa R et al (2005) Association of low adiponectin levels with the metabolic syndrome - the Chennai Urban Rural Epidemiology Study (CURES-4). Metabolism $54: 476-481$

61. Snehalatha C, Mukesh B, Simon M, Viswanathan V, Haffner SM, Ramachandran A (2003) Plasma adiponectin is an independent predictor of type 2 diabetes in Asian Indians. Diabetes Care 26:3226-3229

62. Valsamakis G, Chetty R, McTernan PG, Al-Daghri NM, Barnett AH, Kumar S (2003) Fasting serum adiponectin concentration is reduced in Indo-Asian subjects and is related to HDL cholesterol. Diabetes Obes Metab 5:131-135

63. Chambers JC, McGregor A, Jean-Marie J, Kooner JS (1999) Abnormalities of vascular endothelial function may contribute to increased coronary heart disease risk in UK Indian Asians. Heart 81:501-504

64. Kain K, Catto AJ, Grant PJ (2001) Impaired fibrinolysis and increased fibrinogen levels in South Asian subjects. Atherosclerosis $156: 457-461$ 
65. Nagi DK, Mohamed Ali V, Jain SK, Walji S, Yudkin JS (1996) Plasminogen activator inhibitor (PAI-1) activity is elevated in Asian and Caucasian subjects with non-insulin-dependent (type 2) diabetes but not in those with impaired glucose tolerance (IGT) or non-diabetic Asians. Diabet Med 13:59-64

66. Deepa R, Velmurugan K, Saravanan G, Karkuzhali K, Dwarakanath V, Mohan V (2001) Absence of association between serum homocysteine levels and coronary artery disease in south Indian males. Indian Heart J 53:44-47

67. Chambers JC, Obeid OA, Refsum H et al (2000) Plasma homocysteine concentrations and risk of coronary heart disease in UK Indian Asian and European men. Lancet 355:523-527

68. Boucher BJ, Mannan N, Noonan K, Hales CN, Evans SJ (1995) Glucose intolerance and impairment of insulin secretion in relation to vitamin D deficiency in east London Asians. Diabetologia 38:1239-1245

69. Pittas AG, Li T, Willett WC, Manson JE, Dawson-Hughes B, Hu FB (2005) A prospective study of vitamin D intake and risk of type 2 diabetes in women. Presented at: American Diabetes Association 65th Scientific Session; June 10-14, San Diego, CA: 1772P (Abstract)

70. Ramachandran A, Snehalatha C, Latha E, Satyavani K, Vijay V (1998) Clustering of cardiovascular risk factors in urban Asian Indians. Diabetes Care 21:967-971

71. Tillin T, Forouhi N, Johnston DG, McKeigue PM, Chaturvedi N, Godsland IF (2005) Metabolic syndrome and coronary heart disease in South Asians, African-Caribbeans and white Europeans: a UK population-based cross-sectional study. Diabetologia 48:649-656

72. International Diabetes Federation (2005) The IDF consensus worldwide definition of the metabolic syndrome. Available from http://www.idf.org, last accessed May 2006

73. Kahn R, Buse J, Ferrannini E, Stern M (2005) The metabolic syndrome: time for a critical appraisal: joint statement from the American Diabetes Association and the European Association for the Study of Diabetes. Diabetes Care 28:2289-2304

74. Gale EAM (2005) The myth of the metabolic syndrome. Diabetologia 48:1679-1683

75. Abate N, Carulli L, Cabo-Chan A, Chandalia M, Snell PG, Grundy SM (2003) Genetic polymorphism PC-1 K121Q and the ethnic susceptibility to insulin resistance. J Clin Endocrinol Metab 88:5927-5934

76. Yusuf S, Hawken S, Ounpuu S (2004) Effects of potentially modifiable risk factors associated with myocardial infarction in 52 countries (the INTERHEART study): case-control study. Lancet 364:937-952

77. Gupta R, Singhal S (1997) Coronary heart disease in India. Circulation 96:3785

78. Patel JV, Vyas A, Cruickshank JK et al (2006) Impact of migration on coronary heart disease risk factors: comparison of Gujaratis in Britain and their contemporaries in villages of origin in India. Atherosclerosis 185:297-306

79. Nath BS, Murthy MK (1988) Cholesterol in Indian ghee. Lancet $2: 39$

80. Jacobson MS (1987) Cholesterol oxides in Indian ghee: possible cause of unexplained high risk of atherosclerosis in Indian immigrant populations. Lancet 2:656-658

81. Singh RB, Mori H, Chen J et al (1996) Recommendations for the prevention of coronary artery disease in Asians: a scientific statement of the International College of Nutrition. J Cardiovasc Risk 3:489-494

82. Bhalodkar NC, Blum S, Rana T, Bhalodkar A, Kitchappa R, Enas EA (2005) Effect of leisure time exercise on high-density lipoprotein cholesterol, its subclasses, and size in Asian Indians. Am J Cardiol 96:98-100
83. McKeigue P (2000) Development of interventions to reduce the risk of CHD in South Asians (WE1). The Research Findings Register. Summary number 116. Available from http://www. ReFeR.nhs.uk, last accessed May 2006

84. Heart Protection Study Collaborative Group (2003) MRC/BHF Heart Protection Study of cholesterol-lowering with simvastatin in 5963 people with diabetes: a randomised placebo-controlled trial. Lancet 361:2005-2016

85. Colhoun HM, Betteridge DJ, Durrington PN et al (2004) Primary prevention of cardiovascular disease with atorvastatin in type 2 diabetes in the Collaborative Atorvastatin Diabetes Study (CARDS): multicentre randomised placebo-controlled trial. Lancet 364:685-696

86. Lawrence IG, McNally PG (2001) Heart disease in Asian people with diabetes. Practical Diabetes Int 18:192-196

87. Rubins HB, Robins SJ, Collins D et al (1999) Gemfibrozil for the secondary prevention of coronary heart disease in men with low levels of high-density lipoprotein cholesterol. N Engl J Med 341:410-418

88. FIELD Study Investigators (2005) Effects of long-term fenofibrate therapy on cardiovascular events in 9795 people with type 2 diabetes mellitus (the FIELD Study): randomised controlled trial. Lancet 366:1849-1861

89. Kashyap ML, McGovern ME, Berra K et al (2002) Long-term safety and efficacy of a once-daily niacin/lovastatin formulation for patients with dyslipidemia. Am J Cardiol 89:672678

90. Brown BG, Zhao XQ, Chait A et al (2001) Simvastatin and niacin, antioxidant vitamins, or the combination for the prevention of coronary disease. N Engl J Med 345:1583-1592

91. Hansson L, Zanchetti A, Carruthers SG et al (1998) Effects of intensive blood-pressure lowering and low-dose aspirin in patients with hypertension: principal results of the Hypertension Optimal Treatment (HOT) randomised trial. HOT Study Group. Lancet 351:1755-1762

92. Diabetes UK (2001) Aspirin treatment in diabetes. Available from http://www.diabetes.org.uk/infocentre/carerec/aspirin.htm, last accessed May 2006

93. Ford S, Mai F, Manson A, Rukin N, Dunne F (2000) Diabetes knowledge - are patients getting the message? Int J Clin Pract 54:535-536

94. Hawthorne K (2001) Effect of culturally appropriate health education on glycaemic control and knowledge of diabetes in British Pakistani women with type 2 diabetes mellitus. Health Educ Res 16:373-381

95. Rankin J, Bhopal R (2001) Understanding of heart disease and diabetes in a South Asian community: cross-sectional study testing the 'snowball' sample method. Public Health 115:253260

96. Vyas A, Haidery AZ, Wiles PG, Gill S, Roberts C, Cruickshank JK (2003) A pilot randomized trial in primary care to investigate and improve knowledge, awareness and self-management among South Asians with diabetes in Manchester. Diabet Med 20:1022-1026

97. Patel MG, Wright DJ, Gill PS, Jerwood D, Silcok J, Chrystyn H (2002) Prescribing of lipid lowering drugs so South Asian patients: ecological study. BMJ 325:25-26

98. O'Hare JP, Raymond NT, Mughal S et al (2004) Evaluation of delivery of enhanced diabetes care to patients of South Asian ethnicity: the United Kingdom Asian Diabetes Study (UKADS). Diabetic Med 21:1357-1365

99. Ward PR, Noyce PR, St Leger AS (2005) Multivariate regression analysis of associations between general practitioner prescribing rates for coronary heart disease drugs and healthcare needs indicators. J Epidemiol Community Health 59:86

100. Cruikshank K, Pickup J, Williams G, (eds) (1997) Textbook of diabetes, vol 1, 2nd edn. Blackwell Science, Oxford, p 3.21 